\title{
JD8
}

\section{Stellar Evolution in Real Time}

Chairpersons and Editors: E. F. Guinan \& R. H. Koch 